\title{
High Accuracy of Fluoroscopic Based Navigation of Pedicle Screw Fixation in the Lumbar Spine Utilizing Cylinder Pedicle Design, Innovative Technique
}

\author{
Salah Alakkad MD* \\ Saudi Association of Neurological Surgeons, Saudi Arabia \\ Submission: October 24, 2016; Published: November 07, 2016 \\ *Corresponding author: Salah Alakkad, Saudi Association of Neurological Surgeon, Saudi Arabia, Email: saoa1968@gmail.com
}

\section{Introduction}

Navigation in spine surgery used with different software registration techniques, Fluoroscopic based registration has advantage of easy operation, no need for CT scan, navigating our target without the need to localize, but it miss out the 3rd dimension (axial), so less experienced surgeon may have some difficulty to target a pedicle screw in the lumbar area.

A perfect pedicle screw placement was taught through considering the pedicle as a cylinder to control the trajectory of pedicle screw in the lumbar spine, applying it in practice with standard fluoroscopy was technically demanding tasks since it require 2 simultaneous trajectories and a highly experienced surgeon. In this study we used fluoroscopy based navigation utilizing this idea to make lumbar pedicle screw targeting simple, highly accurate and safe.

\section{Methods}

Using fluoroscopic based navigation utilizing the pedicle cylinder design, 37 consecutive adult cases with 196 lumbar pedicle screws placed in 2 trauma, 7 degenerative/28 with spondylolysthesis grade I, excluded scoliosis, we did fluoroscopic -CT fusion technique on few cases for demonstrative and teaching

purposes to help understanding the idea but the fluoroscopic based navigation was the only images used for targeting the pedicles. A CT scan was done after all cases to check accuracy.

\section{Results}

Misplacement rate was $2.6 \%$, (5screws) 2 screws had cortical encroachment medially (both are L1) the other 3 had lateral minor breach $(<2 \mathrm{~mm})$ to the pedicle (all were $\mathrm{L} 4)$, none resulted in neurological symptoms [1-5].

\section{Learning Objectives}

By the conclusion of this session, participants should be able to:

1. Describe the deferent methods of registration in spine navigation

2. Discuss, the pedicle cylinder design format

3. utilizing the pedicle cylinder design on $2 \mathrm{D}$ fluoroscopic navigation

4. discuss if any other method could be applied (Figure 1 \& 2)

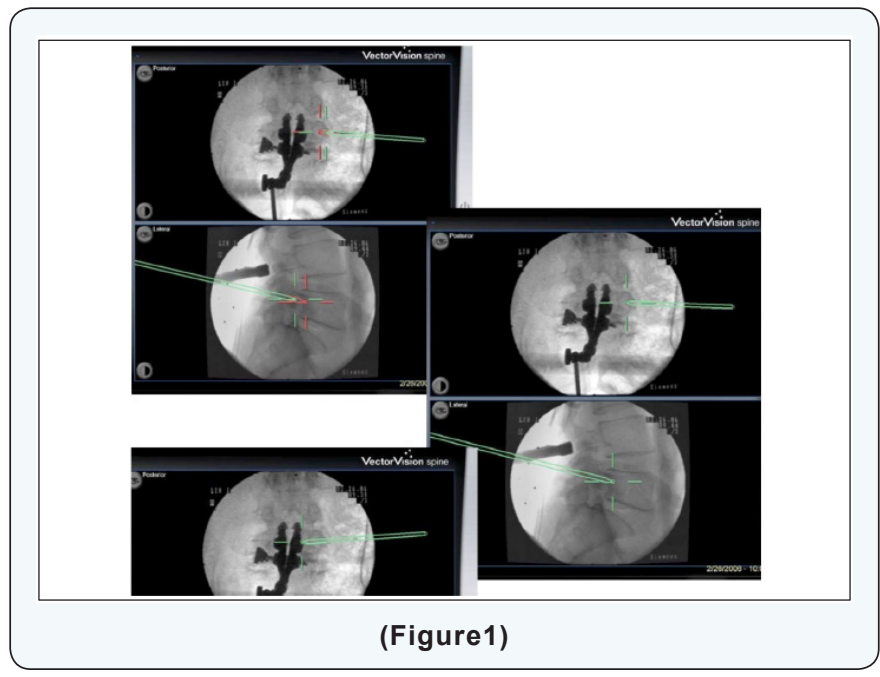




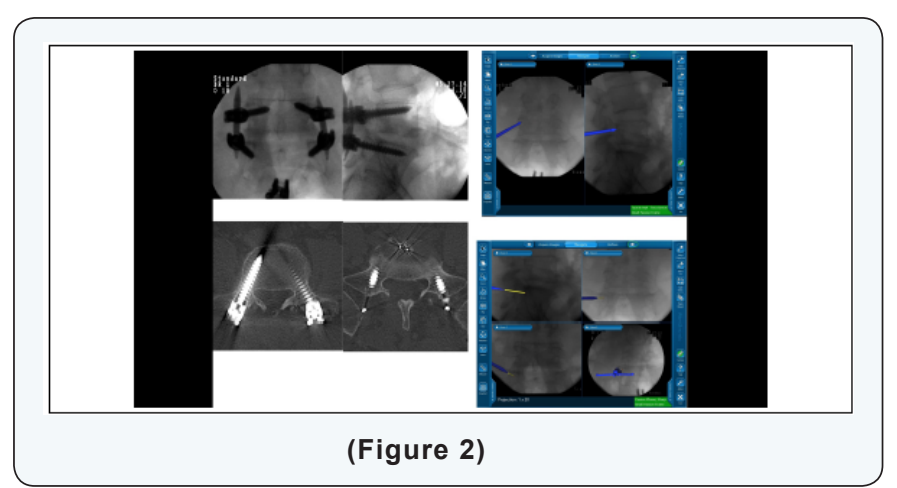

\section{Conclusion}

Using fluoroscopic based navigation on the lumbar spine utilizing pedicle cylinder design is safe and reliable way for targeting lumbar pedicle and may achieve a high level of accuracy, applying Fluoro-CT fusion can be used initially to understand the principle. Pedicle divided into 4 identical quadrants $\backslash$ entries to the pedicle has a medial point, a lateral point and a center in a horizontal meridian AP view, anterior is considered as the isthmus and is seen on a lateral view to cannulate

1. Perfect AP view with sharp upper endplate and centered spinous process and perfect lateral view

2. Place probe at the lateral edge of the horizontal meridian at the AP, which correspond to at the mid cepalocaudal point on the lateral.

3. Elongate virtual probe to Navigate to the center point that is the intersection of both meridian of the pedicle at the isthmus of the pedicle on AP (Figure 3).

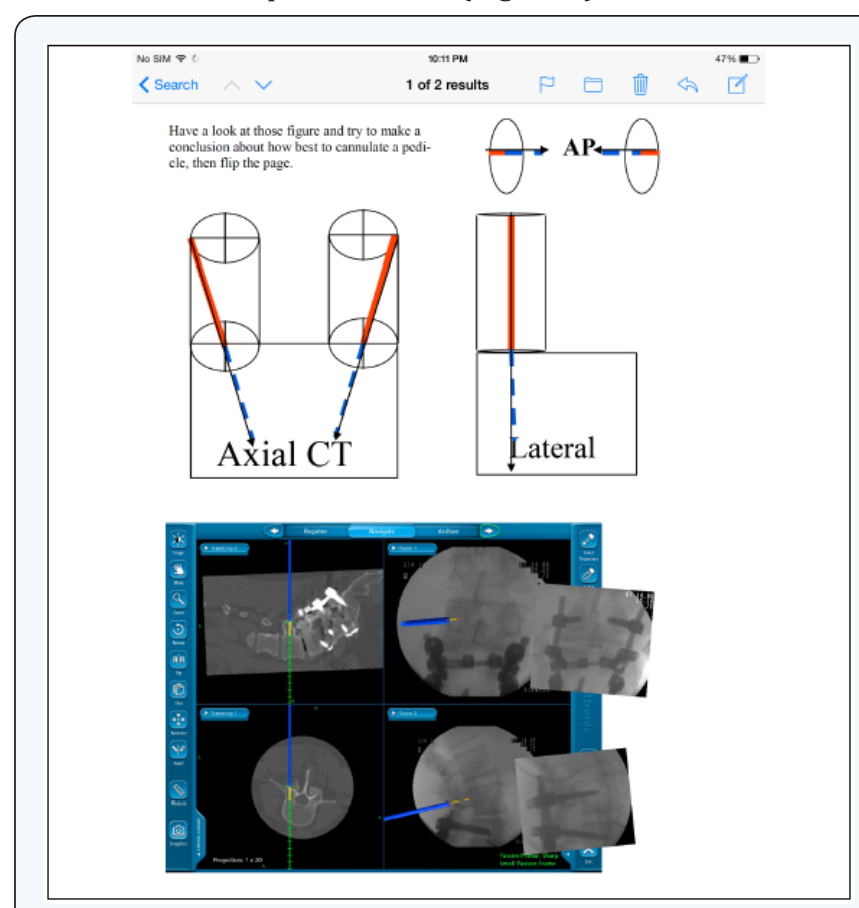

(Figure 3)

\section{References}

1. Yang BP, Wahl MM, Idler CS (2012) Percutaneous lumbar pedicle screw placement aided by computer assisted fluoroscopy-based navigation: perioperative results of a prospective, comparative, multicenter study. Spine 37(24): 2055-2060.

2. Wood M, Mannion R (2011) A comparison of CT-based navigation techniques for minimally invasive lumbar pedicle screw placement. J Spinal Disord Tech 24(1): E1-E5.

3. Laine T, Lund T, Ylikoski M, Lohikoski J, Schlenzka D, et al. (2000) Accuracy of pedicle screw insertion with and without computer assistance: a randomised controlled clinical study in 100 consecutive patients. Eur Spine J 9(3): 235-240.

4. Beck M, Mittlmeier T, Gierer P, Harms C Gradl G, etal. (2009) Benefit and accuracy of intraoperative 3D imaging after pedicle screw placement: a prospective study in stabilizing thoracolumbar fractures. Eur Spine J 18(10): 1469-1477.

5. Gelalis ID, Paschos NK, Pakos EE, Politis AN, Arnaoutoglou CM, et al. (2012) Accuracy of pedicle screw placement: a systematic review of prospective in vivo studies comparing free hand, fluoroscopy guidance and navigation techniques. Eur Spine J 21(2): 247-255.

\section{Your next submission with JuniperPublishers} will reach you the below assets

- Quality Editorial service

- Swift Peer Review

- Reprints availability

- E-prints Service

- Manuscript Podcast for convenient understanding

- Global attainment for your research

- Manuscript accessibility in different formats (Pdf, E-pub, Full Text, Audio)

- Unceasing customer service

Track the below URL for one-step submission http://juniperpublishers.com/online-submission.php 